\section{BMJ Open} Ophthalmology

\title{
Killing efficacy of a new hypothermic corneal storage medium against the micro-organisms frequently found in human donor cornea intended for transplantation
}

\author{
Laura Giurgola, ${ }^{1}$ Claudio Gatto, ${ }^{1}$ Claudia Honisch, ${ }^{2}$ Orietta Rossi, ${ }^{1}$ \\ Eugenio Ragazzi, ${ }^{3}$ Jana D'Amato Tothova (i) ${ }^{1}$
}

To cite: Giurgola L, Gatto C, Honisch C, et al. Killing efficacy of a new hypothermic corneal storage medium against the micro-organisms frequently found in human donor cornea intended for transplantation. BMJ Open Ophthalmology 2021;6:e000833. doi:10.1136/ bmjophth-2021-000833

\section{- Additional supplemental material is published online only. To view, please visit the journal online (http://dx.doi. org/10.1136/bmjophth-2021- 000833).}

Received 18 June 2021 Accepted 27 November 2021

Check for updates

(C) Author(s) (or their employer(s)) 2021. Re-use permitted under CC BY-NC. No commercial re-use. See rights and permissions. Published by BMJ.

${ }^{1}$ R\&D, Alchimia srl, Ponte San Nicolò (PD), Italy

${ }^{2}$ Institute of Biomolecular Chemistry, CNR di Padova, Padova, Italy

${ }^{3}$ Department of Pharmaceutical and Pharmacological Sciences, Università degli Studi di Padova, Padova, Italy

Correspondence to Dr Jana D'Amato Tothova; JTothova@alchimiasrl.com

\section{ABSTRACT}

Objective To study the in vitro killing efficacy of Kerasave (AL.CHI.MI.A SrI), a medium provided with amphotericin B tablet for hypothermic storage of human donor corneas, against relevant contaminants associated with postkeratoplasty infections.

Methods and Analysis The antimicrobial activity of Kerasave was determined after 0,3 and 14 days of incubation at $2^{\circ} \mathrm{C}-8^{\circ} \mathrm{C}$, inoculating Kerasave and the control medium with $10^{5}-10^{6}$ colony forming units (CFU) of Candida albicans (CA), Fusarium solani (FS), Aspergillus brasiliensis (AB), Staphylococcus aureus (SA), Enterococcus faecalis (EF), Bacillus subtilis spizizenii (BS), Pseudomonas aeruginosa (PA), Enterobacter cloacae (EC) and Klebsiella pneumoniae (KP). $\log _{10}$ reductions at different time intervals were determined by assessing the number of viable CFU using the serial dilution plating technique.

Results After 3 days, Kerasave induced the highest $\log _{10}$ decrease in the concentrations of KP, PA, CA and EC (5.37, $4.15,2.97$ and 2.67 , respectively; all $p<0.001)$. The $\log _{10}$ decreases of $S A$ and EF were 2.27 and 2.11, respectively (all $p<0.001$ ). The lowest $\log _{10}$ decrease was observed in $B S, A B$ and $F S$ concentrations $(0.25,0.30$ and 0.67 , respectively; $p<0.001$ for $B S$ and $A B$ and $p=0.004$ for $F S$ ). After 14 days, the microbial count of CA, FS, SA, EF, PA and EC further decreased ( $p=0.006$ for FS; $p<0.001$ for the others).

Conclusion Kerasave effectively reduced or kept unchanged the microbial concentration of almost all tested strains after 3 days. Thus, this novel medium represents a valuable tool to control the microbial contamination of human donor corneas during hypothermic storage for up to 14 days before transplantation.

\section{INTRODUCTION}

The human donor cornea is the most commonly transplanted tissue worldwide. The use of lamellar grafts (eg, Descemet's stripping automated endothelial keratoplasty and Descemet's membrane endothelial keratoplasty) for replacing only the diseased portion of the cornea while sparing the

\section{Key messages}

What is already known about this subject?

- Currently available hypothermic storage media are supplied with antibacterial agents to help reduce the risk of postkeratoplasty bacterial infections, but do not contain antifungal agents.

\section{What are the new findings?}

Kerasave is a new amphotericin B-provided medium for hypothermic storage.

- As shown in in vitro time-kill tests against selected Gram-positive and Gram-negative bacteria and fungi commonly involved in postkeratoplasty infections, Kerasave effectively reduced or kept unchanged the microbial concentration after 3 days.

\section{How might these results change the focus of} research or clinical practice?

This study confirms the killing of the most common contaminants under hypothermic corneal storage even after short incubation times and suggests this medium as a valuable tool to control the microbial contamination of human donor corneas during hypothermic storage before transplantation.

healthy tissue has led to a significant improvement in graft survival and patient outcome..$^{1-3}$ However, corneal transplantation is still associated with a certain risk of postkeratoplasty infections. ${ }^{45}$ Particularly, a trend towards an increase in the incidence of postkeratoplasty fungal infections was observed in the USA. ${ }^{67}$ These cases are mainly related to the procedures of lamellar keratoplasties. ${ }^{8-10}$

Most European eye banks store corneal tissues in organ culture media at $31^{\circ} \mathrm{C}$, containing both antibiotics and antifungal agents to help reduce the risk of microbial proliferation. ${ }^{211}$ Contrarily, eye banks in North America preserve donor corneas at $2^{\circ} \mathrm{C}-8^{\circ} \mathrm{C}$, and the currently available hypothermic 
storage media in the US market are supplied with antibacterial agents ${ }^{12}$ but do not contain antifungal agents. ${ }^{7314}$ For this reason, the possibility of implementing hypothermic corneal storage media with antifungals has a growing interest. ${ }^{613-16}$

Kerasave (AL.CHI.MI.A Srl, Italy) is a newly developed medical device and Conformité Européenne (CE)-marked hypothermic storage medium containing amphotericin $\mathrm{B}$, which is intended for storage of human donor corneas at $2^{\circ} \mathrm{C}-8^{\circ} \mathrm{C}$ for up to 14 days. ${ }^{15}$ Kerasave's Food and Drug Administration approval is pending at the time of this submission.

Previous studies provided evidence of the efficacy and safety of antifungal agents, including amphotericin B, in reducing Candida species contamination of Optisol-GS (Bausch \& Lomb, New Jersey, USA) under hypothermic storage conditions. ${ }^{1314}$ More recently, Tran et al ${ }^{17}$ investigated the efficacy and safety of various concentrations of amphotericin B, including $2.5 \mu \mathrm{g} / \mathrm{mL}$, under hypothermic storage conditions. Our previous studies ${ }^{15} 18$ evaluated the antimycotic efficacy of Kerasave at $2^{\circ} \mathrm{C}-8^{\circ} \mathrm{C}$ against Candida albicans, C. tropicalis and C. glabrata.

The present study aimed to assess the in vitro killing efficacy of Kerasave at $2^{\circ} \mathrm{C}-8^{\circ} \mathrm{C}$ against some clinically relevant contaminants of donor corneas, such as Grampositive Staphylococcus aureus, ${ }^{519-25}$ Enterococcus faecalis ${ }^{23} 24$ and Bacillus subtilis spizizenii ${ }^{22}$; Gram-negative Pseudomonas aeruginosa, ${ }^{5022} 24$ Enterobacter cloacae $e^{23}$ and Klebsiella pneumoniae $^{21}$; and the fungi C. albicans, ${ }^{5123-25}$ Fusarium solan $^{5}$ and Aspergillus brasiliensis. ${ }^{20}$

\section{MATERIALS AND METHODS}

Experimental design

Figure 1 presents the experimental design of the time-kill assay of the present study.

\section{Media and devices}

Kerasave is a Dulbecco's Modified Eagle's Medium-based culture medium containing $6 \%$ dextran, $100 \mu \mathrm{g} / \mathrm{mL}$ gentamicin sulfate and $200 \mu \mathrm{g} / \mathrm{mL}$ streptomycin sulfate. It is supplied with an amphotericin B tablet to be added to the $20 \mathrm{~mL}$ medium before use (final concentration of $2.5 \mu \mathrm{g} / \mathrm{mL}$ ). All vials of Kerasave and blisters containing amphotericin $\mathrm{B}$ tablets were stored at $2^{\circ} \mathrm{C}-8^{\circ} \mathrm{C}$ and protected from light. Each Kerasave sample was prepared under sterile conditions immediately before use by dissolving one tablet of amphotericin $\mathrm{B}$ in the $20 \mathrm{~mL}$ vial containing the Kerasave solution.

RESEP is a syringe-like, patented, CE-marked device containing a resin mixture to remove antimicrobials from the samples. ${ }^{26}$ It has been validated for total elimination of antimicrobials from corneal storage media, ${ }^{27-29}$ including Kerasave (online supplemental tables 1 and 2 ). The validation of the method for removing antimicrobial residues from Kerasave was performed according to the experimental design reported in online supplemental figure 1 . In this study, $6 \mathrm{~mL}$ of each sample were withdrawn using the RESEP syringe and stirred at room

\section{Kerasave time-kill study}

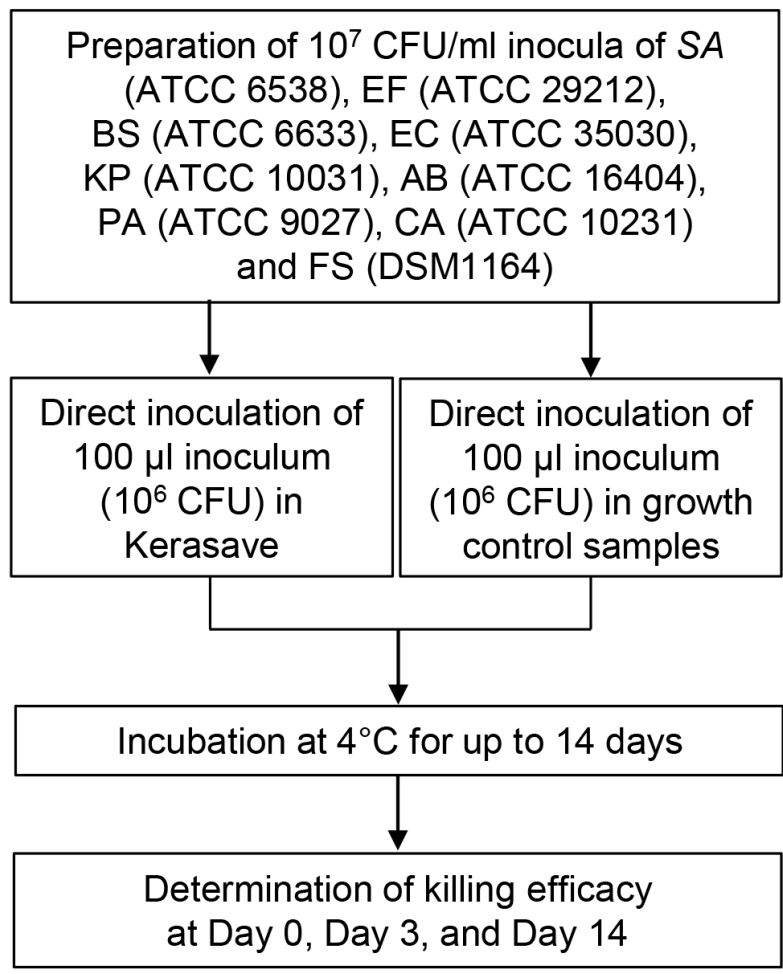

Figure 1 Time-kill experimental design. In the timekill study, $20 \mathrm{~mL}$ of Kerasave and growth controls were inoculated with $10^{6} \mathrm{CFU}$ of tested micro-organisms and incubated at $2^{\circ} \mathrm{C}-8^{\circ} \mathrm{C}$ for up to 14 days. The effective concentration of each micro-organism was determined after 0, 3 and 14 days of incubation. AB, Aspergillus brasiliensis; BS, Bacillus subtilis spizizenii; CA, Candida albicans; CFU, colony forming unit; EC, Enterobacter cloacae; EF, Enterococcus faecalis; FS, Fusarium solani; $\mathrm{KP}$, Klebsiella pneumoniae; PA, Pseudomonas aeruginosa; SA, Staphylococcus aureus; ATCC, American Type Culture Collection; DSM, Deutsche Sammlung von Mikroorganismen.

temperature (RT) for $45 \mathrm{~min}$. Afterwards, the samples were transferred into sterile vials.

\section{Preparation of inocula and growth controls}

$S$. aureus (American Type Culture Collection, ATCC 6538), E. faecalis (ATCC 29212), B. subtilis spizizenii (ATCC 6633), E. cloacae (ATCC 35030), K. pneumoniae (ATCC 10031), A. brasiliensis (ATCC 16404), P. aeruginosa (ATCC 9027) and C. albicans (ATCC 10231) were obtained from Microbiologics (Minnesota, USA). F. solani (Deutsche Sammlung von Mikroorganismen, DSM 1164) was supplied by Leibniz Institute DSMZ-German Collection of Microorganisms and Cell Cultures, Germany.

Inocula of $S$. aureus, E. faecalis, B. subtilis, E. cloacae, A. brasiliensis, $P$. aeruginosa, C. albicans, $K$. pneumoniae and $F$. solani were prepared from lyophilised pellets according to the manufacturer's protocols or from fresh culture according to McFarland standards to obtain $1.0 \times 10^{7}$ colony forming units $(\mathrm{CFU} / \mathrm{mL}$ in physiological solution 
$(0.9 \%(\mathrm{w} / \mathrm{v}) \mathrm{NaCl})$; Merck-Sigma-Aldrich, Darmstadt, Germany.

Tryptone soya broth $(20 \mathrm{~mL}$; Bioculturalab, Italy) was used as growth control for $C$. albicans, A. brasiliensis and $F$. solani, and thioglycolate medium (20 mL; Bioculturalab) was used as growth control for S. aureus, B. subtilis, $P$. aeruginosa and $K$. pneumoniae. Nutrient broth (Nutrient Broth, $20 \mathrm{~mL}$; BioLife, Italy) medium was used as growth control for E. faecalis and E. cloacae.

\section{Time-kill method}

Triplicates of Kerasave samples and growth controls were inoculated with $100 \mu \mathrm{L}$ of inoculum to obtain a final strain concentration of $10^{5}-10^{6} \mathrm{CFU} / \mathrm{mL}$ for each time point. Effective initial strain concentration was determined by counting the number of viable CFU in the $100 \mu \mathrm{L}$ inoculum using the serial dilution plating technique within 3 hours from spiking (day 0 ).

On day 3 and day 14, all Kerasave samples, except those containing $F$. solani, were treated with RESEP before plating to eliminate the antimicrobial residues. Then, the samples were serially diluted in physiological solution and plated on agar plates for viable colony counting. C. albicans and A. brasiliensis were plated on Sabouraud Chloramphenicol Agar Medium (BioLife); S. aureus, B. subtilis, $P$. aeruginosa and $K$. pneumoniae were plated on Trypticase Soy Agar Medium (BioLife); and E. faecalis and E. cloacae were plated on nutrient agar dehydrated medium (BioLife).

On day 3 and day 14, $1 \mathrm{~mL}$ of Kerasave containing $F$. solani was serially diluted in physiological solution and plated on potato glucose agar dehydrated medium (Merck-Sigma-Aldrich). All growth controls were antimicrobial-free, so treatment with RESEP was skipped. At the selected time points, $1 \mathrm{~mL}$ of each growth control was diluted in physiological solution and plated on Petri dishes containing appropriate agar medium as described above. For each condition (i.e., after 3 days and 14 days of incubation at $2^{\circ} \mathrm{C}-8^{\circ} \mathrm{C}$ of Kerasave samples and growth controls, respectively), the concentration of each strain was determined by counting the number of viable CFU in $1 \mathrm{~mL}$ of each sample using the serial dilution plating technique.

Agar plates containing $S$. aureus, B. subtilis, P. aeruginosa, $K$. pneumoniae, E. faecalis and E. cloacae were incubated at $30^{\circ} \mathrm{C}-35^{\circ} \mathrm{C}$ for 24 hours. Plates containing C. albicans and $A$. brasiliensis were incubated at $20^{\circ} \mathrm{C}-25^{\circ} \mathrm{C}$ for up to 72 hours and plates containing $F$. solani at $25^{\circ} \mathrm{C}$ for 5-7 days.

The number of $\mathrm{CFU} / \mathrm{mL}$ in the tested sample corresponding to each plate at each time point was determined using the following formula: $\mathrm{CFU} / \mathrm{mL}=\mathrm{CFU}$ plate $/$ dilution factor.

\section{Statistical analysis}

In previous studies, ${ }^{18}$ the effects observed between the two experimental conditions, Kerasave versus control, were considered 'high' according to the definition by
Cohen. ${ }^{30}$ A preliminary power analysis determined three replicates for each experimental condition as appropriate, considering the low dispersion of the obtained values. Moreover, the use of triplicate samples is an accepted 'rule of the thumb' when sustained by a careful evaluation of characteristics and costs of the experimental design. ${ }^{31}$ The mean $\log _{10}$ reduction was calculated for the tested samples on day 3 and day 14 relative to the initial concentration on day 0 according to Zelver $e t a l^{32}$ using Microsoft Excel V.2010. Mann-Whitney U test was employed to evaluate the $\log _{10}$ reduction by Kerasave against each test organism compared with control on day 3 and day 14. A p value less than or equal to 0.05 was considered statistically significant.

\section{RESULTS}

Table 1 presents the mean concentration $(\mathrm{CFU} / \mathrm{mL})$ and the $\log _{10}$ decrease of all tested strains obtained in growth controls and Kerasave after inoculation with approximately $10^{5}-10^{6} \mathrm{CFU}$; the time-kill curves are presented in figure 2.

Kerasave reduced the concentration of all strains after 3 days of incubation at $2^{\circ} \mathrm{C}-8^{\circ} \mathrm{C}$ (table 1 and figure 2). After 3 days, the highest $\log _{10}$ decrease values were observed for $P$. aeruginos $a$ and $K$. pneumoniae, whereas the lowest values were observed for $A$. brasiliensis, $B$. subtilis and $F$. solani (table 1). After 3 and 14 days of incubation at $2^{\circ} \mathrm{C}-8^{\circ} \mathrm{C}$, differences in the $\log _{10}$ decrease between Kerasave and controls were statistically significant according to Mann-Whitney $U$ test $(\mathrm{p}<0.01$; table 1$)$ for all tested strains, except for $A$. brasiliensis $(\mathrm{p}=0.6396$, MannWhitney $\mathrm{U}$ test), for which a negative $\log _{10}$ decrease was obtained (table 1), corresponding to microbial growth.

After 14 days in Kerasave, the microbial concentration further decreased for all strains, except for B. subtilis, whose extent remained unchanged, $K$. pneumoniae, which was eradicated on day 3 , and $A$. brasiliensis, which showed microbial growth (table 1 and figure 2).

Overall, the microbial concentration remained almost unvaried for all strains in the growth controls, except for A. brasiliensis, E. faecalis and E. cloacae, for which evident growth was observed after 14 days (table 1 and figure 2).

The validation study conducted on RESEP showed effective elimination of the antibiotics from Kerasave and microbial recovery after $45 \mathrm{~min}$ of treatment with RESEP at RT (online supplemental tables 1 and 2), thus complying with the acceptability criteria adopted.

\section{DISCUSSION}

Kerasave is a newly developed medium intended for storage of human donor corneas at $2^{\circ} \mathrm{C}-8^{\circ} \mathrm{C}$ for up to 14 days. This medium has the peculiarity of being supplied with an antifungal amphotericin B tablet. ${ }^{18}$

Unlike our previous study, in which only Candida spp were tested at shorter time intervals, ${ }^{1718}$ the present study investigated nine micro-organisms incubated in Kerasave up to 14 days to simulate the eye bank common practice and cover the intended use of the device. Indeed, 
Table 1 Concentration $(\mathrm{CFU} / \mathrm{mL})$ and $\log _{10}$ decrease obtained in the time-kill studies of Kerasave and growth controls for each strain

\begin{tabular}{|c|c|c|c|c|c|}
\hline \multirow{2}{*}{$\begin{array}{l}\text { Strain and } \\
\text { incubation time } \\
\text { (days) }\end{array}$} & \multicolumn{2}{|c|}{ Mean concentration (CFU/mL) } & \multicolumn{3}{|l|}{$\log _{10}$ decrease } \\
\hline & Growth controls & Kerasave & Growth controls & Kerasave & $P$ value $^{*}$ \\
\hline \multicolumn{6}{|c|}{ Candida albicans ATCC 10231} \\
\hline 0 & $4.45 \times 10^{5} \pm 8.50 \times 10^{4}$ & $4.45 \times 10^{5} \pm 8.50 \times 10^{4}$ & & & \\
\hline 3 & $2.68 \times 10^{5} \pm 4.56 \times 10^{4}$ & $4.83 \times 10^{2} \pm 9.65 \times 10^{1}$ & $0.18 \pm 0.10$ & $2.97 \pm 0.11$ & $<0.001$ \\
\hline 14 & $2.93 \times 10^{5} \pm 6.02 \times 10^{4}$ & $0.18 \times 10^{0} \pm 0.12 \times 10^{0}$ & $0.19 \pm 0.11$ & $5.52 \pm 0.08$ & $<0.001$ \\
\hline \multicolumn{6}{|c|}{ Fusarium solani DSM-N¹164 } \\
\hline 0 & $3.15 \times 10^{5} \pm 9.57 \times 10^{3}$ & $3.15 \times 10^{5} \pm 9.57 \times 10^{3}$ & & & \\
\hline 3 & $2.35 \times 10^{5} \pm 2.09 \times 10^{4}$ & $6.15 \times 10^{4} \pm 3.06 \times 10^{3}$ & $0.13 \pm 0.04$ & $0.67 \pm 0.03$ & 0.004 \\
\hline 14 & $2.12 \times 10^{5} \pm 2.65 \times 10^{4}$ & $1.62 \times 10^{4} \pm 1.07 \times 10^{3}$ & $0.19 \pm 0.05$ & $1.25 \pm 0.03$ & 0.006 \\
\hline \multicolumn{6}{|c|}{ Aspergillus brasiliensis ATCC 16404} \\
\hline 0 & $4.45 \times 10^{5} \pm 6.58 \times 10^{4}$ & $4.45 \times 10^{5} \pm 6.58 \times 10^{4}$ & & & \\
\hline 3 & $1.58 \times 10^{6} \pm 3.89 \times 10^{5}$ & $2.90 \times 10^{5} \pm 6.41 \times 10^{4}$ & $-0.44 \pm 0.13$ & $0.30 \pm 0.14$ & $<0.001$ \\
\hline 14 & $2.03 \times 10^{7} \pm 3.80 \times 10^{6}$ & $2.29 \times 10^{7} \pm 5.07 \times 10^{6}$ & $-1.64 \pm 0.10$ & $-1.62 \pm 0.11$ & 0.640 \\
\hline \multicolumn{6}{|c|}{ Staphylococcus aureus ATCC 6538} \\
\hline 0 & $4.86 \times 10^{5} \pm 5.86 \times 10^{4}$ & $4.86 \times 10^{5} \pm 5.86 \times 10^{4}$ & & & \\
\hline 3 & $8.03 \times 10^{5} \pm 1.50 \times 10^{5}$ & $3.61 \times 10^{3} \pm 7.55 \times 10^{2}$ & $-0.13 \pm 0.12$ & $2.27 \pm 0.11$ & $<0.001$ \\
\hline 14 & $2.27 \times 10^{6} \pm 4.99 \times 10^{5}$ & $1.84 \times 10^{2} \pm 2.39 \times 10^{1}$ & $-0.60 \pm 0.11$ & $3.39 \pm 0.07$ & $<0.001$ \\
\hline \multicolumn{6}{|c|}{ Bacillus subtilis spizizenii ATCC 6633} \\
\hline 0 & $2.13 \times 10^{6} \pm 2.93 \times 10^{5}$ & $2.13 \times 10^{6} \pm 2.93 \times 10^{5}$ & & & \\
\hline 3 & $1.44 \times 10^{7} \pm 4.95 \times 10^{6}$ & $1.01 \times 10^{6} \pm 1.22 \times 10^{5}$ & $-0.51 \pm 0.14$ & $0.25 \pm 0.08$ & $<0.001$ \\
\hline 14 & $3.38 \times 10^{6} \pm 4.60 \times 10^{5}$ & $1.19 \times 10^{6} \pm 1.30 \times 10^{5}$ & $-0.21 \pm 0.09$ & $0.18 \pm 0.08$ & 0.001 \\
\hline \multicolumn{6}{|c|}{ Enterococcus faecalis ATCC 29212} \\
\hline 0 & $4.07 \times 10^{6} \pm 4.04 \times 10^{5}$ & $4.07 \times 10^{6} \pm 4.04 \times 10^{5}$ & & & \\
\hline 3 & $1.93 \times 10^{7} \pm 1.04 \times 10^{6}$ & $3.11 \times 10^{4} \pm 4.72 \times 10^{3}$ & $-0.76 \pm 0.06$ & $2.11 \pm 0.09$ & $<0.001$ \\
\hline 14 & $3.25 \times 10^{10} \pm 5.78 \times 10^{9}$ & $1.20 \times 10^{3} \pm 1.78 \times 10^{2}$ & $-3.91 \pm 0.11$ & $3.53 \pm 0.08$ & $<0.001$ \\
\hline \multicolumn{6}{|c|}{ Pseudomonas aeruginosa ATCC 9027} \\
\hline 0 & $2.10 \times 10^{6} \pm 3.11 \times 10^{5}$ & $2.10 \times 10^{6} \pm 3.11 \times 10^{5}$ & & & \\
\hline 3 & $1.11 \times 10^{6} \pm 2.88 \times 10^{5}$ & $1.73 \times 10^{2} \pm 3.20 \times 10^{1}$ & $0.47 \pm 0.14$ & $4.15 \pm 0.10$ & $<0.001$ \\
\hline 14 & $3.51 \times 10^{6} \pm 7.97 \times 10^{5}$ & $9.78 \times 10^{-1} \pm 1.78 \times 10^{-1}$ & $-0.09 \pm 0.12$ & $6.20 \pm 0.08$ & $<0.001$ \\
\hline \multicolumn{6}{|c|}{ Klebsiella pneumoniae ATCC 10031} \\
\hline 0 & $2.72 \times 10^{5} \pm 2.82 \times 10^{4}$ & $2.72 \times 10^{5} \pm 2.82 \times 10^{4}$ & & & \\
\hline 3 & $2.77 \times 10^{5} \pm 3.70 \times 10^{4}$ & $0.00 \times 10^{0} \pm 0.00 \times 10^{0}$ & $-0.03 \pm 0.06$ & $5.37 \pm 0.04$ & $<0.001$ \\
\hline 14 & $1.83 \times 10^{5} \pm 3.64 \times 10^{4}$ & $0.00 \times 10^{0} \pm 0.00 \times 10^{0}$ & $0.19 \pm 0.07$ & $5.37 \pm 0.04$ & $<0.001$ \\
\hline \multicolumn{6}{|c|}{ Enterobacter cloacae ATCC 35030} \\
\hline 0 & $3.92 \times 10^{5} \pm 5.24 \times 10^{4}$ & $3.92 \times 10^{5} \pm 5.24 \times 10^{4}$ & & & \\
\hline 3 & $2.35 \times 10^{5} \pm 3.23 \times 10^{4}$ & $3.95 \times 10^{3} \pm 1.76 \times 10^{3}$ & $0.16 \pm 0.08$ & $2.67 \pm 0.27$ & $<0.001$ \\
\hline 14 & $8.20 \times 10^{8} \pm 5.87 \times 10^{7}$ & $0.00 \times 10^{0} \pm 0.00 \times 10^{0}$ & $-3.42 \pm 0.06$ & $5.49 \pm 0.05$ & $<0.001$ \\
\hline
\end{tabular}

Data are expressed as mean \pm SEM.

${ }^{\star} \mathrm{P}$ value corresponds to Mann-Whitney $\mathrm{U}$ test on the $\log _{10}$ decrease values between Kerasave and growth controls.

ATCC, American Type Culture Collection; CFU, colony forming unit; DSM, Deutsche Sammlung von Mikroorganismen.

the release of the cornea for transplantation usually does not exceed 7 days of storage at $4{ }^{\circ} \mathrm{C},{ }^{2}$ and the maximum time of use of the device indicated by the manufacturer corresponds to 14 days. Therefore, in the present study, data were not acquired beyond 14 days. All the tested micro-organisms showed significantly lower microbial concentrations in Kerasave than in the growth controls of all the tested time points, except for A. brasiliensis on day 14, which was comparable with the control. Our findings indicated that the medium effectively eliminated 

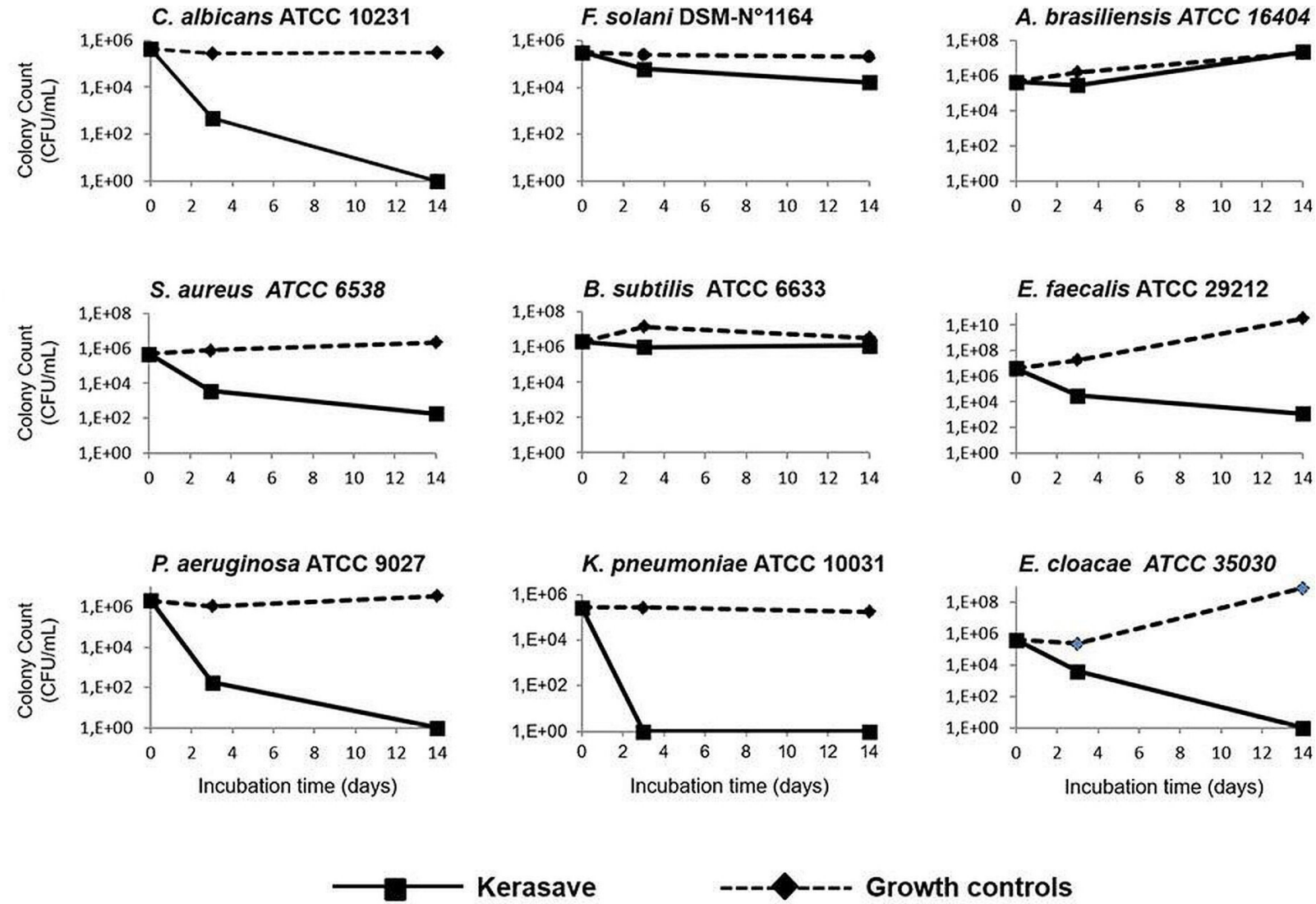

------ Growth controls

Figure 2 Time-kill curves. The graphs show the mean values of microbial concentration, expressed as $\mathrm{CFU} / \mathrm{mL}$, observed in the Kerasave samples and growth controls on day 0 , day 3 and day 14 for each tested micro-organism. CFU, colony forming unit. ATCC, American Type Culture Collection; DSM, Deutsche Sammlung von Mikroorganismen.

seven out of nine $(78 \%)$ tested micro-organisms. This was accomplished despite the low storage temperature of $4^{\circ} \mathrm{C}$, which is considered to be a condition resulting in poor antimicrobial efficacy. ${ }^{11} 33$

The bactericidal activity is achieved when a $3 \log _{10}$ decrease is obtained. ${ }^{34-36}$ In the time-kill assay, a very high initial microbial concentration inoculum $\left(10^{5}-\right.$ $10^{6} \mathrm{CFU} / \mathrm{mL}$ ) is used to allow quantification of the killing efficacy. The high inoculum concentration used in our study does not reflect a clinical situation as it is significantly higher than the bacterial concentration observed in the blood of patients with sepsis $\left(10^{2}-10^{3} \mathrm{CFU} / \mathrm{mL}\right)^{37}$; therefore, complete elimination of the tested micro-organism is not expected in these assays. In our study, the $3 \log _{10}$ decrease indicates bactericidal activity of Kerasave for some micro-organisms. Complete microbial elimination (5-6 $\log _{10}$ reduction) would correspond to the performance of disinfectants and sterilisation processes, which is not expected to be achieved by Kerasave.

A $\log _{10}$ reduction $\geq 3$ was achieved after 3 days of incubation in Kerasave for C. albicans, P. aeruginosa and $K$. pneumoniae strains, and was achieved on day 14 for S. aureus, E. faecalis and E. cloacae. The elimination of C. albicans was in line with the results of our previous study, in which C. albicans killing was assessed after 10 days of incubation. ${ }^{18}$ In this study, Kerasave was shown to be effective during the 14 days of storage. For three strains (A. brasiliensis, F. solani and B. subtilis), a low or negative $\log _{10}$ decrease was observed, which indicated low microbial elimination or slight microbial growth over time. For both A. brasiliensis and F. solani, which are filamentous fungi, a low killing efficacy of $2.5 \mu \mathrm{g} / \mathrm{mL}$ amphotericin B contained in Kerasave was expected as the minimal inhibition concentration values for amphotericin B reported in the literature were $0.03-4 \mu \mathrm{g} / \mathrm{mL}$ and $4-8 \mu \mathrm{g} / \mathrm{mL}$ for $A$. brasiliensis and $F$. solani, respectively. ${ }^{38-41}$ In a previous study, Duncan $e t a l^{42}$ found that the supplementation of the hypothermic corneal storage medium with amphotericin B at $0.25 \mu \mathrm{g} / \mathrm{mL}$ effectively reduced the growth of $F$. solani.

Along with the lower concentration of amphotericin $\mathrm{B}$, there are some other differences in the experimental conditions between this and our study, that is, a lower concentration of the inoculum $\left(2.5 \times 10^{3} \mathrm{CFU} / \mathrm{mL}\right.$ vs $10^{5}-10^{6} \mathrm{CFU} / \mathrm{mL}$ ) and a lower extent of growth reduction. Nevertheless, the authors also concluded that amphotericin B appeared to be a reasonable candidate drug for an antifungal additive to a corneal storage medium. In a recent study, Kaymar et $a l^{43}$ found that amphotericin B at $2.5 \mu \mathrm{g} / \mathrm{mL}$ was ineffective in eliminating small loads of Candida and Fusarium species (up to $10^{3} \mathrm{CFU} / \mathrm{mL}$ ). However, the goal of that study was to achieve complete elimination of fungi limited 
to single testing due to the scarcity of corneal tissue. Unlike our study, the growth reduction was not quantified. Thus, the differences in the experimental design might explain why the authors concluded that the eradication of fungal contamination of donor corneal tissue might require complementary approaches of antifungal supplementation of hypothermic storage media. However, based on the results of Kapur et al's study, ${ }^{44}$ which examined the effect of the hypothermic corneal storage medium with and without tissue growth of similar species, it appears that the presence of corneal tissue does not affect viable counts.

The concentration of amphotericin B in Kerasave represents the optimal balance between the efficacy and safety for preserving the donor cornea ${ }^{17}$ and was selected under the intended use of Kerasave, which corresponds to corneal storage rather than corneal disinfection. Although corneal disinfection as intended for disinfectants (povidone-iodine solutions) is out of Kerasave's intended use, ${ }^{18}$ Kerasave temporarily prevented the growth of $F$. solani, for which a moderate $1.25 \log _{10}$ decrease was observed after 14 days. In any case, we can consider Kerasave effective in decreasing or eliminating contamination from Candida spp, which is the most commonly encountered pathogen. ${ }^{7}$ Other fungi were not commonly encountered in donor corneal transplantation. ${ }^{232445}$

Surprisingly, a very low $\log _{10}$ decrease of 0.18 was observed for B. subtilis after 14 days in Kerasave, indicating a bacteriostatic rather than bactericidal effect for this strain under the tested conditions. Data in the literature reported $B$. subtilis to be sensitive to gentamicin $(4.0 \mathrm{mg} / \mathrm{L} ; 0.125 \mu \mathrm{g} / \mathrm{mL})$ and resistant to streptomycin ${ }^{45-47}$; the gentamicin content of Kerasave, which is significantly higher than that reported in the literature, led us to expect higher killing efficacy of $B$. subtilis spizizenii by Kerasave. The low killing efficacy was confirmed when we repeated the time-kill assay at $4^{\circ} \mathrm{C}$ and $31^{\circ} \mathrm{C}$ after 3 days of incubation to evaluate whether the incubation temperature could influence the killing efficacy of Kerasave (data not shown). At $31^{\circ} \mathrm{C}$, a 0.6 $\log _{10}$ decrease was observed in Kerasave after 3 days, whereas marked growth was observed in controls $(-2.8$ $\log _{10}$ decrease; data not shown). We thus confirmed the bacteriostatic effect of Kerasave for $B$. subtilis under tested conditions. Moreover, we hypothesised that $B$. subtilis spizizenii can turn into sporulation, enabling survival under adverse conditions. ${ }^{48}{ }^{49}$ However, microscopy studies to check for possible B. subtilis spizizenii sporulation were not conducted as they were beyond the scope of the present study.

With regard to growth controls, most strains maintained the initial concentration or showed growth along with incubation (A. brasiliensis, E. faecalis and $E$. (loacae). Previous studies ${ }^{15}{ }^{42}$ compared Kerasave with other corneal storage media. Contrarily, in this study, we chose to use growth media as control samples to confirm microbial growth of the strains under tested conditions and not in comparison with other corneal storage media since the validity of the time-kill assay and evaluation of the recovery of viable micro-organisms require optimal microbial growth and absence of any factors that would interfere with it. As discussed by Tran et $a l,{ }^{17}$ approaches that do not use a step to neutralise the antimicrobials present in the culture samples used for the quantification of the micro-organisms can lead to the presence of some residual amounts of drugs, which can prevent growth on culture plates. ${ }^{17}$ Kerasave contains different antimicrobials, and their interference with microbial growth is predictable. Therefore, to avoid false-negative results, RESEP was used before plating the Kerasave samples on agar plates. The treatment of Kerasave samples with RESEP was validated prior to its use in the time-kill assay using the ultra-high-performance liquid chromatography which revealed total removal of antimicrobials from Kerasave and complete recovery of viable micro-organisms was obtained in RESEP-treated or untreated samples (online supplemental tables 1 and 2).

The RESEP treatment was not performed on $F$. solani containing samples since growth inhibition of $F$. solani by Kerasave was not observed. Thus, the dilution plate technique was sufficient to obtain a reliable result in the time-kill study.

Safety study of Kerasave was out of the scope of the present study as it has been previously investigated in cells via a cytotoxicity test, biocompatibility animal studies according to International Organization for Standardization standards ${ }^{1718}$ and in donor corneas. ${ }^{1545}$

This study completes the data obtained in our previous work on the efficacy of the Kerasave medium, confirming the killing of the most common corneal contaminants by Kerasave under hypothermic corneal storage conditions even after a short incubation time (C. albicans, $P$. aeruginosa and $K$. pneumoniae) and preventing the microbial growth of all the other tested strains. In this study, the killing efficacy of Kerasave was directly related to the time of incubation, as observed for $S$. aureus, E. faecalis and E. cloacae. The killing efficacy of Kerasave could be limited in case of contaminations by micro-organisms resistant to the antimicrobials present in Kerasave (amphotericin B, streptomycin sulfate and gentamicin sulfate), and eye banks should consider that a short storage interval and storage temperature of $4^{\circ} \mathrm{C}$ could prevent the eradication of high contamination from donor tissues. ${ }^{18}$ Finally, the hypothermic corneal storage medium Kerasave is a promising tool for enhancing the safety of the recipient of the transplanted cornea.

Acknowledgements The authors thank Cristina Gianotti for writing assistance.

Contributors LG and JD'AT planned and designed the study, analysed and interpreted the data, drafted the manuscript, and critically revised the manuscript. CG, LG, OR and CH performed the experiments. $\mathrm{CH}$ and ER analysed and interpreted the data and critically revised the manuscript. JD'AT is responsible for the overall content as guarantor. 
Funding The authors have not declared a specific grant for this research from any funding agency in the public, commercial or not-for-profit sectors.

Competing interests LG, CG, OR and JD'AT are employed by the company that was involved in the development of the medical device discussed in the present paper.

Patient consent for publication Not required

Ethics approval This study does not involve human participants.

Provenance and peer review Not commissioned; externally peer reviewed.

Data availability statement Data are available upon reasonable request.

Supplemental material This content has been supplied by the author(s). It has not been vetted by BMJ Publishing Group Limited (BMJ) and may not have been peer-reviewed. Any opinions or recommendations discussed are solely those of the author(s) and are not endorsed by BMJ. BMJ disclaims all liability and responsibility arising from any reliance placed on the content. Where the content includes any translated material, BMJ does not warrant the accuracy and reliability of the translations (including but not limited to local regulations, clinical guidelines, terminology, drug names and drug dosages), and is not responsible for any error and/or omissions arising from translation and adaptation or otherwise.

Open access This is an open access article distributed in accordance with the Creative Commons Attribution Non Commercial (CC BY-NC 4.0) license, which permits others to distribute, remix, adapt, build upon this work non-commercially, and license their derivative works on different terms, provided the original work is properly cited, appropriate credit is given, any changes made indicated, and the use is non-commercial. See: http://creativecommons.org/licenses/by-nc/4.0/.

ORCID iD

Jana D'Amato Tothova http://orcid.org/0000-0003-1498-615X

\section{REFERENCES}

1 Reinhart WJ, Musch DC, Jacobs DS, et al. Deep anterior lamellar keratoplasty as an alternative to penetrating keratoplasty a report by the American Academy of ophthalmology. Ophthalmology 2011;118:209-18.

2 Armitage WJ. Preservation of human cornea. Transfus Med Hemother 2011;38:143-7.

3 Tan DTH, Dart JKG, Holland EJ, et al. Corneal transplantation. Lancet 2012;379:1749-61.

4 Rehany U, Balut G, Lefler E, et al. The prevalence and risk factors for donor corneal button contamination and its association with ocular infection after transplantation. Cornea 2004;23:649-54.

5 Chen JY, Jones MN, Srinivasan S, et al. Endophthalmitis after penetrating keratoplasty. Ophthalmology 2015;122:25-30.

6 Aldave AJ, DeMatteo J, Glasser DB, et al. Report of the eye bank association of America medical Advisory board Subcommittee on fungal infection after corneal transplantation. Cornea 2013;32:149-54.

7 Thareja T, Kowalski R, Kamyar R, et al. Fungal infection after keratoplasty and the role of antifungal supplementation to storage solution: a review. Br J Ophthalmol 2020;104:1-4

8 Fontana L, Moramarco A, Mandarà E, et al. Interface infectious keratitis after anterior and posterior lamellar keratoplasty. clinical features and treatment strategies. A review. $\mathrm{Br} J$ Ophthalmol 2019;103:307-14.

9 Palioura S, Sivaraman K, Joag M, et al. Candida endophthalmitis after Descemet stripping automated endothelial keratoplasty with grafts from both eyes of a donor with possible systemic candidiasis. Cornea 2018;37:515-8.

10 Brothers KM, Shanks RMQ, Hurlbert S, et al. Association between fungal contamination and eye bank-prepared endothelial keratoplasty tissue: temperature-dependent risk factors and antifungal supplementation of Optisol-gentamicin and streptomycin. JAMA Ophthalmol 2017;135:1184-90.

11 Pels E, Beele H, Claerhout I. Eye bank issues: II. Preservation techniques: warm versus cold storage. Int Ophthalmol 2008;28:155-63.

12 Hassan SS, Wilhelmus KR, Medical Review Subcommittee of the Eye Bank Association of America. Eye-banking risk factors for fungal endophthalmitis compared with bacterial endophthalmitis after corneal transplantation. Am J Ophthalmol 2005;139:685-90.

13 Duncan K, Parker J, Hoover C, et al. The effect of light exposure on the efficacy and safety of amphotericin B in corneal storage media. JAMA Ophthalmol 2016;134:432-6.
14 Layer N, Cevallos V, Maxwell AJ, et al. Efficacy and safety of antifungal additives in Optisol-GS corneal storage medium. JAMA Ophthalmol 2014;132:832-7.

15 Mistò R, Giurgola L, Pateri F, et al. A new storage medium containing amphotericin B versus Optisol-GS for preservation of human donor corneas. Br J Ophthalmol 2020;0. doi:10.1136/ bjophthalmol-2020-317136. [Epub ahead of print: 10 Nov 2020].

16 Doshi H, Pabon S, Price MO, et al. Overview of systemic Candida infections in hospital settings and report of candida after DMEK successfully treated with antifungals and partial graft excision. Cornea 2018;37:1071-4

17 Tran KD, Aldrich BT, D'Amato Tóthová J, et al. Efficacy and safety of various amphotericin B concentrations on Candida albicans in cold storage conditions. Cornea 2020;39:110-7.

18 Giurgola L, Gatto C, Parel J-M, et al. Antimycotic efficacy and safety of a new cold corneal storage medium by time-kill and toxicity studies. Cornea 2019;38:1314-21.

19 Escapini H, Olson RJ, Kaufman HE. Donor cornea contamination with McCarey-Kaufman medium preservation. Am J Ophthalmol 1979:88:59-62.

20 Poole TG, Insler MS. Contamination of donor cornea by gentamicinresistant organisms. Am J Ophthalmol 1984;97:560-4.

21 Pardos GJ, Gallagher MA. Microbial contamination of donor eyes. Arch Ophthal 1982;100:1611-3.

22 Albon J, Armstrong M, Tullo AB. Bacterial contamination of human organ-cultured corneas. Cornea 2001;20:260-3.

23 Broniek G, Langwińska-Wośko E, Sybilska M, et al. Prevalence of bacteria and fungi in samples of cornea preservation fluid. Arch Med Sci 2018;14:541-6.

24 Fontana L, Errani PG, Zerbinati A, et al. Frequency of positive donor rim cultures after penetrating keratoplasty using hypothermic and organ-cultured donor corneas. Cornea 2007;26:552-6.

25 Zanetti E, Bruni A, Mucignat G, et al. Bacterial contamination of human organ-cultured corneas. Cornea 2005;24:603-7.

26 Buzzi M, Guarino A, Gatto C, et al. Residual antibiotics in decontaminated human cardiovascular tissues intended for transplantation and risk of falsely negative microbiological analyses. PLoS One 2014;9:e112679.

27 Mistò R, Giurgola L, Pateri F, et al. Method for sterility testing of corneal storage and transport media after removal of interfering antimicrobials: prospective validation study in compliance with the European Pharmacopoeia. BMJ Open Ophthalmol 2017;2:e000093.

28 Vignola R, Mistò R, Giurgola L, et al. A two-centre validation study of sterility test of corneal storage media with elimination of interfering antimicrobials in compliance with the European Pharmacopoeia. Cell Tissue Bank 2019:20:275-85.

29 Skenderi Z, Giurgola L, Gatto C, et al. Increased sensitivity of microbiological testing of cornea organ culture medium by additional resin treatment. BMJ Open Ophthalmol 2018;3:e000173.

30 Cohen J. Statistical power analysis for the behavioral sciences. Hillsdale, NJ: Erlbaum, 1988.

31 Singer JM, Pedroso-de-Lima AC, Tanaka NI, et al. To triplicate or not to triplicate? Chemometrics and Intelligent Laboratory Systems 2007;86:82-5.

32 Zelver N, Hamilton M, Goeres D, et al. Development of a standardized antibiofilm test. Methods Enzymol 2001;337:363-76.

33 Pitt TL, Tidey K, Roy A, et al. Activity of four antimicrobial cocktails for tissue allograft decontamination against bacteria and Candida spp. of known susceptibility at different temperatures. Cell Tissue Bank 2014;15:119-25.

34 Leite MCA, Bezerra APdeB, de Sousa JP, et al. Evaluation of antifungal activity and mechanism of action of citral against Candida albicans. Evid Based Complement Alternat Med 2014;2014:378280.

35 Pfaller MA, Sheehan DJ, Rex JH. Determination of fungicidal activities against yeasts and molds: lessons learned from bactericidal testing and the need for standardization. Clin Microbiol Rev 2004:17:268-80.

36 Van Dijck P, Sjollema J, Cammue BP, et al. Methodologies for in vitro and in vivo evaluation of efficacy of antifungal and antibiofilm agents and surface coatings against fungal biofilms. Microb Cell 2018:5:300-26.

37 Yagupsky P, Nolte FS. Quantitative aspects of septicemia. Clin Microbiol Rev 1990;3:269-79.

38 Tokarzewski S, Ziółkowska G, Nowakiewicz A. Susceptibility testing of Aspergillus niger strains isolated from poultry to antifungal drugs-a comparative study of the disk diffusion, broth microdilution (M 38-A) and Etest methods. Pol J Vet Sci 2012;15:125-33.

39 Borman AM, Fraser M, Palmer MD, et al. MIC distributions and evaluation of fungicidal activity for amphotericin $B$, itraconazole, voriconazole, posaconazole and caspofungin and 20 species of 
pathogenic filamentous fungi determined using the CLSI broth microdilution method. J Fungi 2017;3:27.

40 Lass-Flörl C, Mayr A, Perkhofer S, et al. Activities of antifungal agents against yeasts and filamentous fungi: assessment according to the methodology of the European Committee on antimicrobial susceptibility testing. Antimicrob Agents Chemother 2008;52:3637-41.

41 Lalitha P, Shapiro BL, Srinivasan M, et al. Antimicrobial susceptibility of Fusarium, Aspergillus, and other filamentous fungi isolated from keratitis. Arch Ophthalmol 2007;125:789-93.

42 Duncan K, Parker J, Hoover C, et al. Efficacy of amphotericin B against Fusarium and Aspergillus in corneal storage medium. Eye Contact Lens 2018;44:390-2.

43 Kaymar RM, Shatten JD D, et al. Washing to dilute may be the answer to eliminate fungus from donor corneal tissue. Int $J$ Eye Banking 2020;8.

44 Kapur R, Tu EY, Pendland SL, et al. The effect of temperature on the antimicrobial activity of Optisol-GS. Cornea 2006;25:319-24.

45 Perry I, Peterson K, Tóthová Jana D'Amato, et al. Performance of new hypothermic corneal storage media with an antimycotic tablet in comparison to traditional hypothermic media during simulated eye bank processing. Cornea 2020;39:1031-9.

46 Adimpong DB, Sørensen KI, Thorsen L, et al. Antimicrobial susceptibility of Bacillus strains isolated from primary starters for African traditional bread production and characterization of the bacitracin operon and bacitracin biosynthesis. Appl Environ Microbiol 2012;78:7903-14.

47 Lin JT, Connelly MB, Amolo C, et al. Global transcriptional response of Bacillus subtilis to treatment with subinhibitory concentrations of antibiotics that inhibit protein synthesis. Antimicrob Agents Chemother 2005;49:1915-26.

48 Budde I, Steil L, Scharf C, et al. Adaptation of Bacillus subtilis to growth at low temperature: a combined transcriptomic and proteomic appraisal. Microbiology 2006;152:831-53.

49 Jabbari S, Heap JT, King JR. Mathematical modelling of the sporulation-initiation network in Bacillus subtilis revealing the dual role of the putative quorum-sensing signal molecule PhrA. Bull Math Biol 2011;73:181-211. 